\title{
An Optimized Direct Control Method Applied to Multilevel Inverter for Microgrid Power Quality Enhancement
}

\author{
Yahya Naderi ${ }^{1,2}$, Seyed Hossein Hosseini ${ }^{1,3}$, Saeid Ghassem Zadeh ${ }^{1, *}$, Behnam Mohammadi-Ivatloo ${ }^{1}$ \\ Mehdi Savaghebi ${ }^{2}$ Josep M. Guerrero ${ }^{2}$ \\ ${ }^{1}$ Faculty of Electrical and Computer Engineering, University of Tabriz, Tabriz, Iran \\ ${ }^{2}$ Department of Energy Technology, Aalborg University, Aalborg, Denmark \\ ${ }^{3}$ Engineering Faculty, Near East University, 99138 Nicosia, North Cyprus, Mersin 10, Turkey \\ *Corresponding Author
}

\begin{abstract}
Multifunctional DGs and active power filters have become a mature technology in recent years, so in this paper, an optimized current control method for a multilevel converter is proposed to overcome harmonic current tracking inefficiency of previous control methods in online harmonic compensation applications in microgrids. This control method is applicable for grid-connected inverter-based multifunctional Distributed Generation (DG) converters. It could also be used in active power filter applications which need high-speed reference tracking ability. Having the advantages of current control methods like hysteresis band control, proportional-integral PI and Proportional + Resonant (PR) control methods, it overcomes disadvantages of these methods especially in harmonic reference tracking as it will be discussed in detail. The main advantages of this method are the simplicity of implementation, calculation delay compensation and its fast response to changes. The power electronic circuit, operating principles, two-horizon predicted switching states of MLI, experimental results and applications of this control method will be discussed in the paper. For studying the feasibility of the control method, a prototype of this converter is tested in a microgrid platform.
\end{abstract}

Index Terms - AC microgrid, Power Quality; Multilevel Inverter; Optimal Direct Control (ODC); Harmonic Compensation; Computational delay compensation, two-horizon MPC

\section{INTRODUCTION}

Multilevel inverters are among the most popular inverters especially for medium and high voltage applications. Multilevel inverters has been introduced by Nabae et al. and has gained increasing attention between researchers for its unique characteristics such as higher output power quality, higher efficiency, low harmonic components, lower switching losses and lower $d i / d t$ or $d v / d t$, which is making multilevel inverters viable alternatives for most of the applications [1-4]. Many topologies and control methods are suggested for these inverters in different applications; some of these methods are concentrated on harmonic elimination such as selective harmonic 
elimination method (SHEM), due to applicability limitations, it is not a convenient method for real-time harmonic compensating applications [5-7]. In some harmonic compensation applications such as active power filter and microgrid control, online control methods such as hysteresis band control and P+Resonant control methods are popular [8-12]. Several control methods have been used to control the power quality improvement devices such as STATCOM, DSTATCOM or UPQC (unified power quality conditioner) [13-15]. Each of the mentioned control methods has its advantages and disadvantages; hysteresis band control method needs a high band-width inverter output while having a very fast dynamic response to load and reference changes. Beyond its simplicity of implementation, the P+Resonant controller has disadvantage of using many parallel resonant controllers for tracking the references of multiple harmonic orders, and it will increase the computational burdens. Meanwhile, it does not have a very good dynamic response because of its integrator blocks. Some hierarchical control methods are improved to control the multi-functional DGs, but they also have the disadvantage of slow dynamic response to changes [16]. Thanks to improvements in computational capabilities in recent years, application of optimal direct control methods such as model predictive control has become popular because of simplicity of control, lower average switching frequency, excellent dynamic response, and independency of controller design to load changes and not using the modulation block. During recent years, the researchers have strongly promoted the control method although it has attracted some criticisms from others. In some references, it is shown that the finite control set model predictive based controller (FCS-MPC) and other linear methods (PR and PI controllers) could be viewed as a special case of MPC [17]. In first years of development, MPC was used for solving optimization-based problems or as an energy management solution [18]. Later on, it was spread to be used in power electronic applications such as single phase and three phase inverters control, multilevel and matrix converters control and every model-based optimization problem which involves optimal decision making [19-23] . Another important advantage of MPC is to deal with complex non-linear situations and output an optimized multiobjective solution for the problem [24, 25]. A disadvantage of direct control methods such as MPC is the computational delay that is negligible when using high-performance controllers or considering the controller ideal. How to solve this problem for normal processors will be discussed in Section 2.3. In this paper, the aim is to control a multifunctional DG that plays the role of an improved active power filter, which will be responsible for harmonic compensation and load feeding. The interfacing converter for this purpose will be a multilevel converter for which the application in power quality improvement in microgrids will be discussed. Furthermore, an improved optimal direct control method will be implemented to a cascaded H-Bridge to compensate the harmonics in a microgrid while feeding the linear and non-linear loads. In the next section, the test system will be presented, this will be followed by a brief explanation of multilevel inverter working principles, and then optimal direct control method and how to apply it to a cascaded H-bridge to control the output current will be presented. Finally, experimental results will verify the applicability of the control method. 


\section{POWER SySTEM MODELING AND MATHEMATICAL EQUATIONS}

The system under study is a single-phase grid-connected AC microgrid including a DG which is connected to the grid through a cascaded H-Bridge multilevel inverter, linear and nonlinear loads. As it could be seen in Fig. 1, the nonlinear load is connected to PCC and will draw harmonic current from grid, making grid current non-sinusoidal. So, the aim of this paper is to generate the harmonic current drawn by non-linear load by DG units, so that the grid current will be harmonic free. The reference current for multilevel inverter will include the harmonic load current as well as fundamental load current and also the current that will be injected into the grid;

$$
\begin{aligned}
I_{r e f} & =I_{\text {ref_f }}+I_{\text {ref } \_\mathrm{h}} \\
& =I_{L L}+I_{\text {grid }}+I_{N L L}
\end{aligned}
$$

In which $I_{L L}$ and $I_{\text {grid }}$ are linear load current and the injected current to grid, $I_{N L L}$ is the non-linear load which contains fundamental and harmonic current.

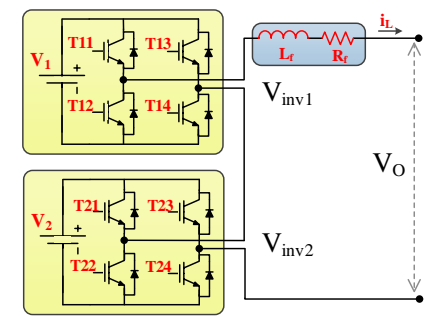

Fig. 1. Multilevel inverter used as a DG interface

As it could be seen in Fig. 2, the main objective is to have a harmonic free grid current (current injected into the grid). Therefore, DG unit will be a multifunctional DG which will act as an active power filter while it is also injecting active and reactive power to the local loads. The multifunctional DG is connected to the main grid through a multilevel inverter and will inject harmonic current to microgrid to feed both linear and non-linear load to prevent the grid current from becoming polluted with harmonics. The current reference to be tracked is calculated as it is shown in (1) and it includes the fundamental term as well as harmonic current terms.

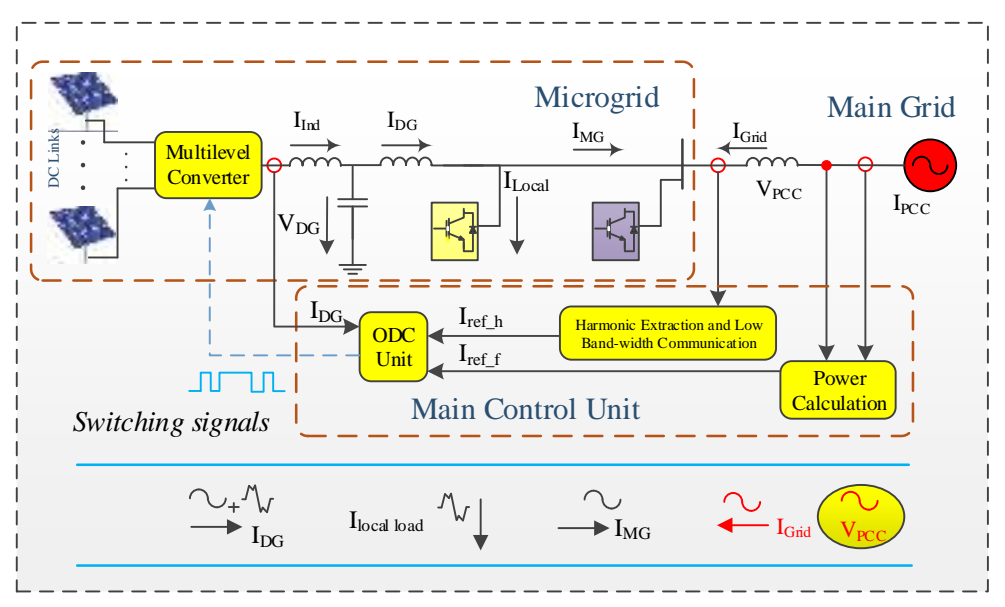

Fig. 2. Test system 


\subsection{Power Electronic Converter}

The power electronic interface used to connect the DG to the microgrid is a multilevel inverter as shown in Fig. 1 . This inverter is a series connection of two basic units with two unequal DC sources that can produce nine levels of output voltage steps using eight unidirectional power electronic switches and eight anti-parallel diodes, the switching states of this inverter is shown in Table I. It is worth noting that the switches in each inverter legs are working in a complementary way, such that when $T_{11}$ is on, $T_{12}$ is off accordingly and vice versa and it is the same for other legs also [3]. It is worth mentioning that to increase the number of levels that could be generated by this multilevel inverter to decrease total harmonic distortion (THD), the values of DC source magnitudes are unequal and calculated as (2), although there are several methods to calculate values of DC sources for multilevel converters, the one generating the maximum number of output voltage levels with the same number of DC sources and power electronic elements have been used in this paper [26].

$$
\begin{aligned}
& V_{1}=V_{d c} \\
& V_{2}=3 V_{d c}
\end{aligned}
$$

Table I presents the switching pattern for the cascaded H-bridge inverter and also the output voltage value for each step is introduced in this table. As it was mentioned before and could be seen in Table I, the switches in each leg of the converter are working in a complementary way.

Table I. Switching States of Multilevel inverter

\begin{tabular}{|c|c|c|c|c|c|}
\hline \multicolumn{5}{|c|}{ Switching States } & \multicolumn{2}{c}{} \\
\hline & & & & State & Voltage \\
$\mathrm{T}_{24}$ & $\mathrm{~T}_{21}$ & $\mathrm{~T}_{14}$ & $\mathrm{~T}_{11}$ & $\left(j_{k}\right)$ & Steps \\
\hline 1 & & & & 1 & +4 \\
\hline 1 & 1 & 1 & 0 & 2 & +3 \\
\hline 1 & 1 & 0 & 0 & 3 & +2 \\
\hline 1 & 0 & 1 & 1 & 4 & +1 \\
\hline 1 & 0 & 1 & 0 & 5 & 0 \\
\hline 1 & 0 & 0 & 0 & 6 & -1 \\
\hline 0 & 0 & 1 & 1 & 7 & -2 \\
\hline 0 & 0 & 1 & 0 & 8 & -3 \\
\hline 0 & 0 & 0 & 0 & 9 & -4 \\
\hline
\end{tabular}




\subsection{Power Converter Control Concept}

The optimal direct current control method applied to a multilevel inverter is presented in this paper. This method could control the output fundamental current as well as harmonic current. The basic idea to control the converter by optimal direct control is the fact that the output state of current could be assumed equal in a very small time interval [16];

$$
\begin{aligned}
& \text { if } T s \rightarrow 0 \\
& I(k+1)=I(k)
\end{aligned}
$$

The optimal direct power control method proposed in this paper, which in fact is a division of the finite control set model predictive control (FCS-MPC), has the advantage of dealing with finite number of switching states of a power converter for solving the optimization problem. FCS-MPC is applying optimal switching signals directly to power electronic converters without the need for a modulation stage. The concept of FCS-MPC is to model the non-linear converters and based on the discrete linearized model of the converter, decides which switching pattern should be applied to get the optimal output result. In the case of power electronic converters, a relevant cost function is formed, based on discrete model of the converter the future behavior of converter is forecasted. After forecasting the converter behavior and applying it to the cost function, the control actions that best fit to minimize the cost function in each time interval $T_{S}$ will be the desired control set. This cycle will repeatedly be done in each sampling interval so that the optimum function of the converter is guaranteed.

A typical and simple cost function is normally a positive sum of the tracking errors for each controlled variable so that a one-horizon cost function could be defined as (4) [27, 28]. This method is called short prediction horizon. However, it is possible to increase the prediction horizons to have long horizon prediction $(n \geq 2)$ in FCS-MPC method, because the computational burden is not so high [29, 30]. It is verified in [31] that long prediction horizon has better steady-state performance while increasing the calculations significantly.

$$
g[\mathrm{~K}]=\left\|\mathrm{X}_{(\mathrm{k}+1)}^{\prime}-\mathrm{X}_{(\mathrm{k}+1)}^{*}\right\|_{2}^{2}
$$

In which $x_{(k+1)}^{\prime}$ is the predicted output of the converter and $x_{(k+1)}^{*}$ is the reference value to be tracked and $\|\cdots \cdots\|_{2}^{2}$ is the quadratic Euclidean norm, i.e.

$$
\left\|x-x^{*}\right\|_{2}^{2}=\left(x_{1}-x_{1}^{*}\right)^{2}+\cdots+\left(x_{n}-x_{n}^{*}\right)^{2}
$$

For a pair of vectors $x^{*}, x$, in some applications cost function could be a multi-objective equation such as a sum of several numbers of $\|\cdots-\cdots\|_{2}^{2}$. 
For a multilevel inverter, a discrete equation modeling the operation could be expressed as equation set (6), in this equation $V_{k}$ and $I_{k}$ are the inverter output voltage and current. $R_{f} \mathrm{i}_{\mathrm{L}}$ the output filter resistance while $L_{f}$ is the output filter inductance as shown in Fig. 1 and $T_{S}$ is the time instant in which optimization is being done.

$$
V_{\text {inv } 1}[k]+V_{\text {inv } 2}[k]-V_{O}[k]=V_{L}[k]+\left(R_{f} \times I_{L}[k]\right)=L_{f} \times\left(\frac{I_{L}[k+1]-I_{L}[k]}{T_{S}}\right)
$$

From equation (6), $I_{L(K+1)}$ could be calculated as:

$$
I_{L}[k+1]=\left(1-\frac{R_{f} \times T_{S}}{L_{f}}\right) \times I_{L}[k]+\frac{T_{S}}{L_{f}} \times\left(V_{i n v 1}[k]+V_{i n v 2}[k]-V_{O}[k]\right)
$$

A function Based on the possible output voltage values, $I_{L}[k+1]$ will be predicted for the instant $\mathrm{k}+1$, and the optimal switching state will be selected as shown in Fig. 3. During the optimization process, all of the nine possible states for switches are calculated and by replacing the predicted current $I_{L}[k+1]$ in equation (4) the optimal state which minimizes the error of cost function will be selected as the switching state and the output current will track the reference current. The accuracy of tracking is highly dependent on switching frequency (optimization period) but as a common solution, maximum switching frequency of $f_{S}=10 \mathrm{KHz}$ will give enough precession for most of the applications [16].

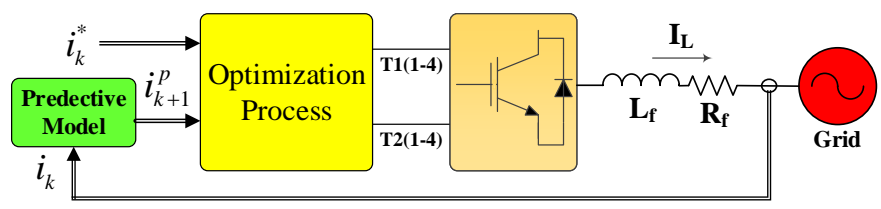

Fig. 3. Predictive control scheme

Since the presented multilevel inverter has nine possible switching states, the predictive model will generate an array including nine possible values for $I_{L}[k+1]$ in each step, based on the cost function, optimization block will decide which switching state to apply to minimize the tracking error.(8) and (9) present the value of $V_{i n v 1}[\mathrm{k}]+V_{i n v 2}[\mathrm{k}]$ as a function of switching states, in which $j_{k}=1: 9$ represent the sum of output voltage for cascaded H-bridge converters, as shown in

\section{Table II.}

$$
\begin{aligned}
& V_{i n v 1,2}[\mathrm{k}]=V_{i n v 1}[\mathrm{k}]+V_{i n v 2}[\mathrm{k}] \\
& =S\left(j_{k}\right) \times \mathrm{V}_{\mathrm{dc}} \\
& \left\{\begin{array}{l}
S\left(j_{k}\right)=\left(j_{k}-5\right) \\
j_{k}=1: 9
\end{array}\right.
\end{aligned}
$$


Table II. Different switching states in two-horizon prediction for cascaded H-bridge multilevel inverter

\begin{tabular}{|c|c|c|c|c|c|c|c|c|c|c|}
\hline \multicolumn{4}{|c|}{ Horizon $1 *$} & \multicolumn{4}{|c|}{ Horizon $2^{* *}$} & \multicolumn{3}{|c|}{ Values } \\
\hline$\exists$ & $\stackrel{\Xi}{E}$ & $\vec{N}$ & $\stackrel{\stackrel{\sim}{N}}{\leftrightarrows}$ & $\exists$ & $\stackrel{\Xi}{\Xi}$ & $\vec{N}$ & $\stackrel{\text { I }}{=}$ & $S\left(j_{k}\right.$ & $S\left(j_{k+1}\right)$ & $S\left(j_{k+2}\right)$ \\
\hline 1 & 1 & 1 & 1 & 1 & 1 & 1 & 1 & 4 & 4 & 8 \\
\hline$\vdots$ & $\vdots$ & $\vdots$ & $\vdots$ & $\vdots$ & $\vdots$ & : & $\vdots$ & $\vdots$ & $\vdots$ & $\vdots$ \\
\hline 1 & 1 & 1 & 1 & 0 & 0 & 0 & 0 & 4 & -4 & 0 \\
\hline 1 & 1 & 1 & 0 & 1 & 1 & 1 & 1 & 3 & 4 & 7 \\
\hline : & : & $:$ & $:$ & : & : & : & $:$ & $:$ & $:$ & $\vdots$ \\
\hline 1 & 1 & 1 & 0 & 0 & 0 & 0 & 0 & 3 & -4 & -1 \\
\hline 1 & 1 & 0 & 0 & 1 & 1 & 1 & 1 & 2 & 4 & 6 \\
\hline$\vdots$ & $\vdots$ & : & : & : & $\vdots$ & : & $\vdots$ & $\vdots$ & $\vdots$ & $\vdots$ \\
\hline 1 & 1 & 0 & 0 & 0 & 0 & 0 & 0 & 2 & -4 & -2 \\
\hline 1 & 0 & 1 & 1 & 1 & 1 & 1 & 1 & 1 & 4 & 5 \\
\hline$\vdots$ & $\vdots$ & : & : & : & $\vdots$ & : & $\vdots$ & $\vdots$ & $\vdots$ & $\vdots$ \\
\hline 1 & 0 & 1 & 1 & 0 & 0 & 0 & 0 & 1 & -4 & -3 \\
\hline 1 & 0 & 1 & 0 & 1 & 1 & 1 & 1 & 0 & 4 & 4 \\
\hline$\vdots$ & $\vdots$ & : & : & : & $\vdots$ & : & $\vdots$ & $:$ & $\vdots$ & $\vdots$ \\
\hline 1 & 0 & 1 & 0 & 0 & 0 & 0 & 0 & 0 & -4 & -4 \\
\hline 1 & 0 & 0 & 0 & 1 & 1 & 1 & 1 & -1 & 4 & 3 \\
\hline$\vdots$ & $\vdots$ & : & $:$ & : & $\vdots$ & $:$ & $\vdots$ & $\vdots$ & $\vdots$ & $\vdots$ \\
\hline 1 & 0 & 0 & 0 & 0 & 0 & 0 & 0 & -1 & -4 & -5 \\
\hline 0 & 0 & 1 & 1 & 1 & 1 & 1 & 1 & -2 & 4 & 2 \\
\hline$:$ & $:$ & $:$ & : & : & : & : & : & : & $\therefore$ & $:$ \\
\hline 0 & 0 & 1 & 1 & 0 & 0 & 0 & 0 & -2 & -4 & -6 \\
\hline 0 & 0 & 1 & 0 & 1 & 1 & 1 & 1 & -3 & 4 & 1 \\
\hline$:$ & $:$ & : & $:$ & $:$ & $:$ & $:$ & : & $:$ & $:$ & $:$ \\
\hline 0 & 0 & 1 & 0 & 0 & 0 & 0 & 0 & -3 & -4 & -7 \\
\hline 0 & 0 & 0 & 0 & 1 & 1 & 1 & 1 & -4 & 4 & 0 \\
\hline$\vdots$ & $\vdots$ & : & $:$ & : & $\vdots$ & : & $\vdots$ & $\vdots$ & $\vdots$ & $\vdots$ \\
\hline 0 & 0 & 0 & 0 & 0 & 0 & 0 & 0 & -4 & -4 & -8 \\
\hline
\end{tabular}

* Horizon 1 represents the interval between $\mathrm{t}_{k-1}$ and $\mathrm{t}_{k}$

** Horizon 2 represents the interval between $t_{k}$ and $t_{k+1}$

In fact for calculation of cost function for all possible switching states, it will take some time based on the capability of the processor, this time delay will cause a steady state error in tracking the reference for the controller, in the next section how to compensate this delay will be discussed in details. Replacing k with $\mathrm{k}+1$ in (7) $I_{L}[k+2]$ will be defined as, 


$$
I_{L}[k+2]=\left(1-\frac{R_{f} \times T_{S}}{L_{f}}\right) \times I_{L}[k+1]+\frac{T_{S}}{L_{f}} \times\left(V_{i n v 1}[k+1]+V_{i n v 2}[k+1]-V_{o}[k+1]\right)
$$

\subsection{Optimal Direct Control Delay Compensation}

Depending on the processor calculation speed and the maximum switching frequency, the time between the measurement of the output current and application of the new switching states to the inverter will be considerable, if the calculation time is comparable to sampling time, there will be a delay in switching of the inverter which will cause consistent tracking error in the output current, because in the instant $k+1$ the previous switching state is applied to the inverter which will lead to increase or decrease of output current more than the reference current increase or decrease [24, 32]. It is known that by using long-horizon prediction FCS-MPC this delay will be omitted, but as the number of prediction horizons is increasing, the controller complexity is increasing exponentially, so a trade-off should be done between the number of horizons to be predicted and controller complexity. To deal with this problem an improvement to a twohorizon prediction method is presented in this paper which was first proposed in [33], so that the processor has enough time to do the calculation and prediction for the instant $k+2$, between instants $k$ and $k+1$ and finally apply the new switching states at instant $k+2$ as it is shown in Fig. 4.. 

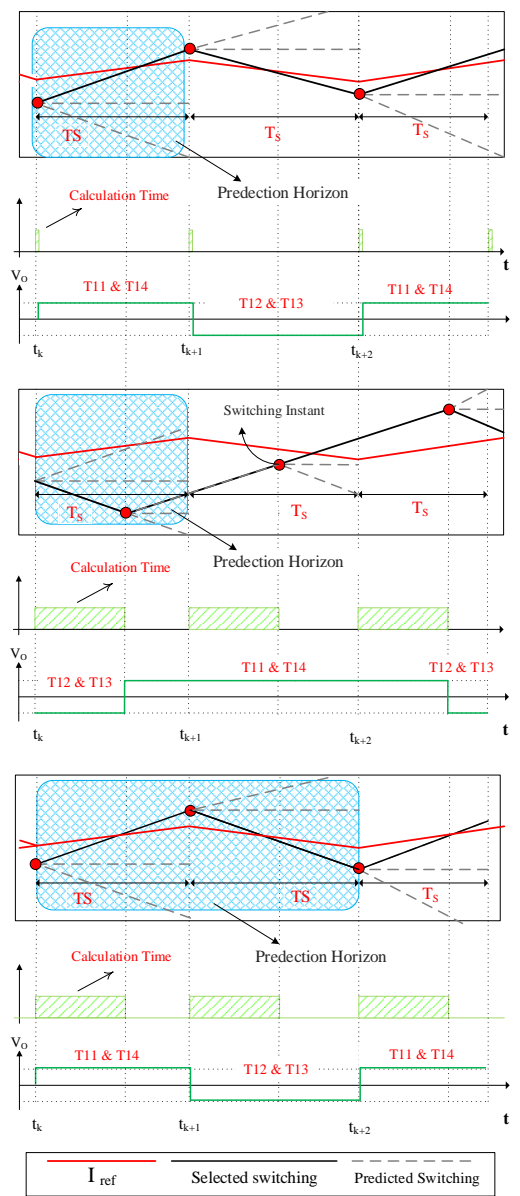

Fig. 4. Operation of the Model predictive controller with three Scenarios (a) without Delay (ideal case) (b) with delay and without delay compensation (c) with delay and two horizon prediction to compensate delay.

In this method, the measurements are performed in instant $\mathrm{k}$, then the predictions are being done to calculate $I_{L}^{*}[k+1]$. Then, the calculated $I_{L}^{*}[k+1]$ will be used to predict $I_{L}^{*}[k+2]$, after calculation of $I_{L}^{*}[k+2]$ both current reference for instant k+2 and the predicted value of current $I_{L}^{*}[k+2]$ will be fed to the optimization block to decide which switching state will minimize the cost function. This explanation will be clearly understood by considering the equation below and checking out the flowchart view of the applied twohorizon control method as shown in Fig. 5. 


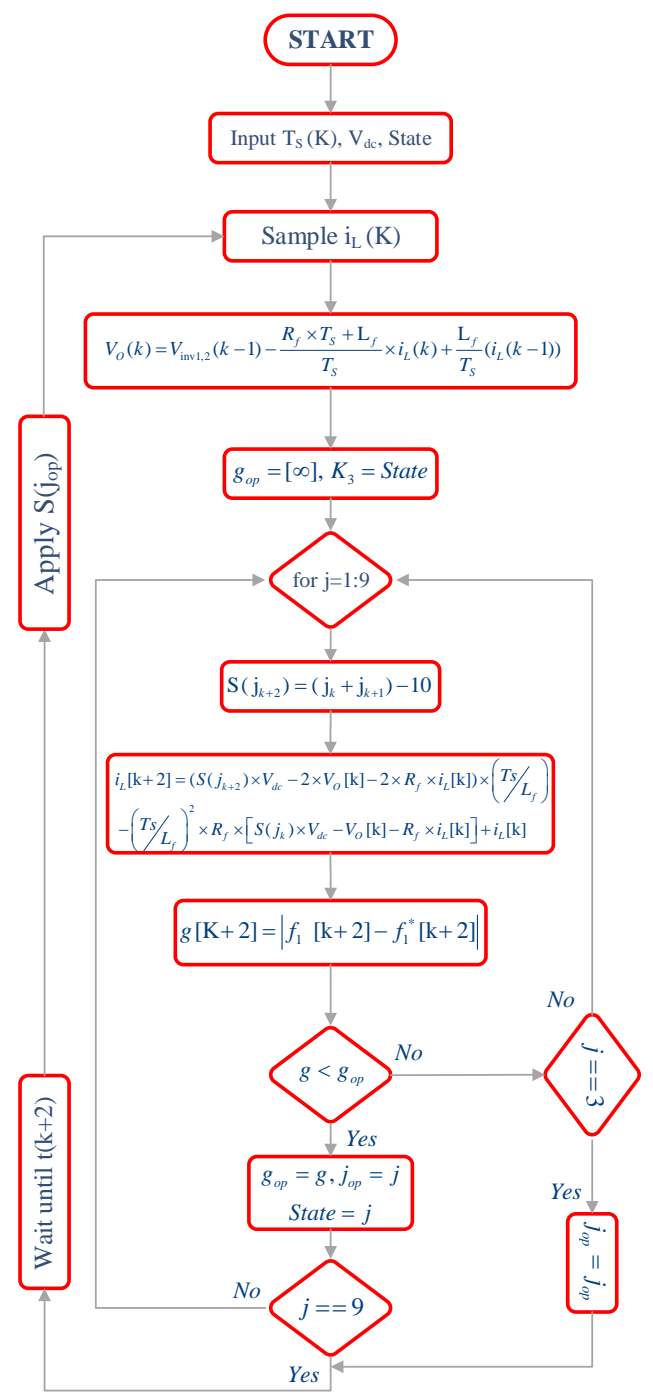

Fig. 5. Flowchart view of the applied optimal direct control for multilevel inverter

By replacing (7) into (10), $I_{L}[k+2]$ could be written as;

$$
i_{L}[\mathrm{k}+2]=\left(V_{i n v 1,2}[\mathrm{k}]+V_{i n v 1,2}[\mathrm{k}+1]-2 \times V_{O}[\mathrm{k}]-2 \times R_{f} \times i_{L}[\mathrm{k}]\right) \times \frac{T_{S}}{L_{f}}-\left(\frac{T_{S}}{L_{f}}\right)^{2} \times R_{f} \times\left[V_{i n v 1,2}[\mathrm{k}]-V_{O}[\mathrm{k}]-R_{f} \times i_{L}[\mathrm{k}]\right]+i_{L}[\mathrm{k}]
$$

To simplify the equation, a function $S\left(j_{k+2}\right)$ that relates the output voltage value of the two cascaded H-bridges at previous switching state to the predicted output voltage value is defined to replace the term $V_{i n v 1,2}[\mathrm{k}]+V_{i n v 1,2}[\mathrm{k}+1]$ as

$$
V_{i n v 1,2}[\mathrm{k}]+V_{i n v 1,2}[\mathrm{k}+1]=\mathrm{S}\left(\mathrm{j}_{k+2}\right) \times \mathrm{V}_{d c}
$$

In which 


$$
\left\{\begin{array}{l}
\mathrm{S}\left(\mathrm{j}_{k+2}\right)=\mathrm{S}\left(\mathrm{j}_{k}\right)+\mathrm{S}\left(\mathrm{j}_{k+1}\right)=\left(\mathrm{j}_{k}+\mathrm{j}_{k+1}\right)-10 \\
j_{k}=1: 9 \\
j_{k+1}=1: 9
\end{array}\right.
$$

Considering equations (11) and (12), the final equation describing $I_{L}[k+2]$ will be as;

$$
i_{L}[\mathrm{k}+2]=\left(S\left(j_{k+2}\right) \times V_{d c}-2 \times V_{o}[\mathrm{k}]-2 \times R_{f} \times i_{L}[\mathrm{k}]\right) \times \frac{T_{S}}{L_{f}}-\left(\frac{T_{S}}{L_{f}}\right)^{2} \times R_{f} \times\left[S\left(j_{k}\right) \times V_{d c}-V_{o}[\mathrm{k}]-R_{f} \times i_{L}[\mathrm{k}]\right]+i_{L}[\mathrm{k}]
$$

It should be mentioned that an improvement to the previously presented delay compensation method has been done by (14) that creates a direct relation between $I_{L}[k+2]$ and $I_{L}[k]$, which, unlike the traditional model predictive control will not increase the complexity of implementation and computational burden much when applying two-horizon prediction. By applying this method, the calculation delay will be almost compensated.

Table II presents different switching states in two-horizon prediction for a cascaded H-bridge multilevel converter, as it can be seen there are 81 possible switching states for converter with 64 duplicate states, which will finally lead to 17 distinct switching states.

As it could be seen in Fig. 5 the modified control method is as follows,

1. Measurement of the load currents $\left(i_{L}(k)\right)$

2. Calculation of $V_{s}(k)$ based on the previous interval data

3. Calculation of the currents at the instant $t_{k+1}$ based on the applied switching state of previous interval

4. Prediction of load currents at the instant $t_{k+2}$ for all switching states based on calculated $i_{L}(k+1)$ to speed up the control process steps 3 and 4 could be merged so that the calculations and predictions are done at once Equation (14)

5. Evaluation of the cost function for all predicted currents at instant $t_{k+2}$

6. Selection of the switching state that minimizes the cost function and applying it to converter

\section{EXPERIMENTAL RESULTS}

To verify the feasibility of the proposed control scheme for the multilevel inverter shown in Fig. 1, different test scenarios are performed using the prototype shown in Fig. 6. As it can be seen in Fig. 6 the test system includes a two-input multilevel cascaded H-bridge converter supplied by isolated DC sources, linear load, AC programmable load as non-linear load, digital control platform, digital to analog (DAC) boards and finally a regenerative high power grid simulator that emulates the behavior of the real electrical grid. Provided test results 
are using a digital oscilloscope and power quality analyzer. Detailed specifications of the experimental prototype are as shown in Table III. Experimental tests are performed in three different scenarios, in the first scenario the operation of MLI converter without non-linear load is studied, the second scenario focuses on verifying the efficiency of control method in operation of the MLI converter as an advanced active power filter to share the power and compensate the harmonics, finally in the third scenario the control method is analyzed based on dynamic response of the inverter to the changes occurred in reference current or grid voltage. It should be noted that the mentioned switching frequency in Table III is the maximum switching frequency that is used in the switching process, and the average switching frequency for this converter is calculated, and it is around $3.5 \mathrm{kHz}$.

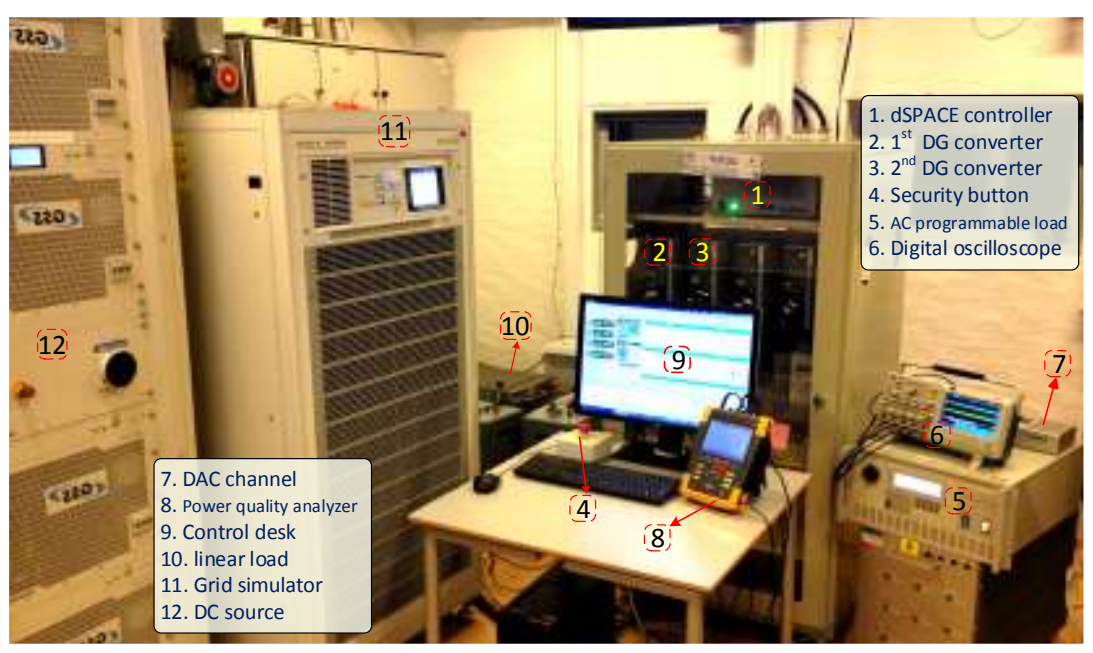

Fig. 6. A prototype of the proposed test system

Table III. SPECIFICATIONS OF THE EXPERIMENTAL SETUP

\begin{tabular}{ccc}
\hline \hline Parameter & Value & Unit \\
\hline \hline Power Grid Voltage & 110 & $\mathrm{~V}(\mathrm{RMS})$ \\
\hline Grid Frequency & 50 & $\mathrm{~Hz}$ \\
\hline Maximum output power & 0.8 & $\mathrm{~kW}$ \\
\hline DC Link Voltage & 195 & $\mathrm{~V}$ \\
\hline Maximum switching frequency & 10 & $\mathrm{kHz}$ \\
\hline Sampling frequency & 20 & $\mathrm{kHz}$ \\
\hline Inverter Side inductance & 8.6 & $\mathrm{mH}$ \\
\hline Grid Side Resistance & 0.2 & $\Omega$ \\
\hline
\end{tabular}




\begin{tabular}{ccc}
\hline Non-linear Load Spec & $* \mathrm{CF}=2.0$ & $* * \mathrm{PF}=1$ \\
\hline Non-linear Load Mag (RMS) & 1.54 & $\mathrm{~A}$ \\
\hline *: Crest Factor & $* *$ : Power Factor
\end{tabular}

\subsection{The grid-tie operation of MLI converter}

In this scenario, grid-tie operation of the multilevel converter with optimal direct control method to track the sinusoidal current reference

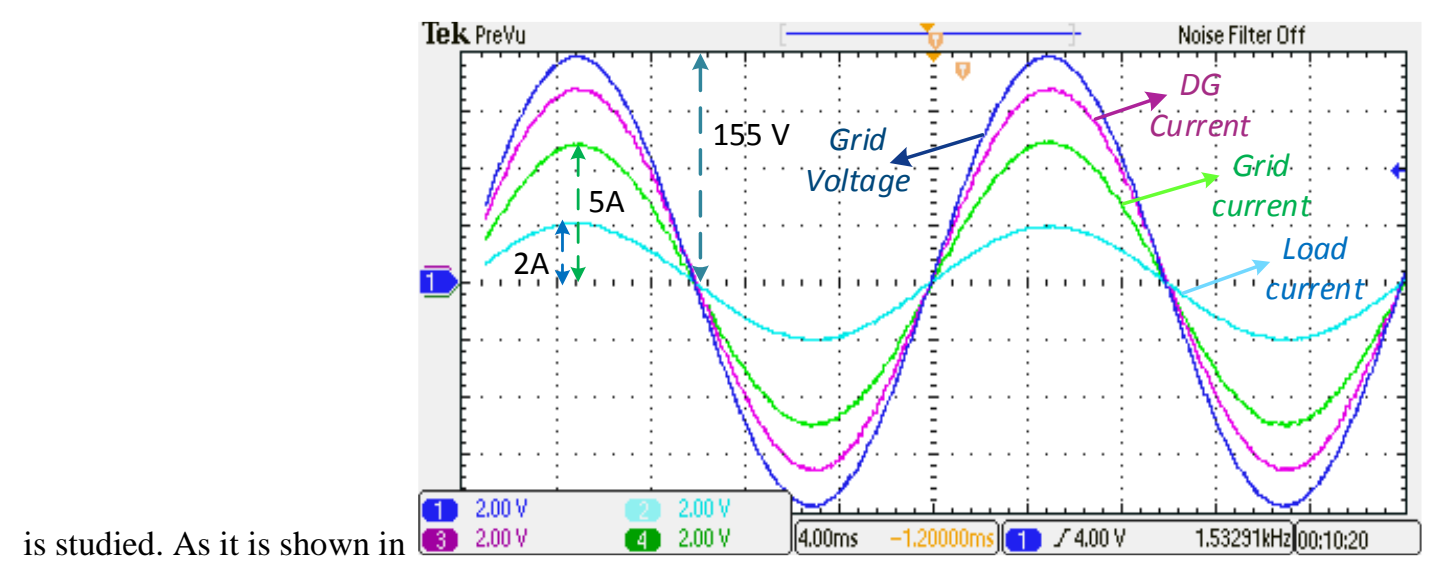

Fig. 7 grid injected current is almost sinusoidal with the THD of $2.1 \%$, DG current is feeding the linear load, and it is also injecting the current to the grid which is in phase with grid voltage. Grid Voltage and DG current waveform are shown in Fig. 8(a), which is followed by the harmonic spectrum measured by power quality analyzer in Fig. 8(b). Total harmonic distortion of the grid current is $2.1 \%$ which is below the limits defined by IEEE power quality standard [34]. It is obvious that by increasing the switching frequency THD value will even decrease to a lower amount which will lead to higher switching losses, so there should be a trade-off to have an in-range total harmonic distortion using a reasonable switching frequency.

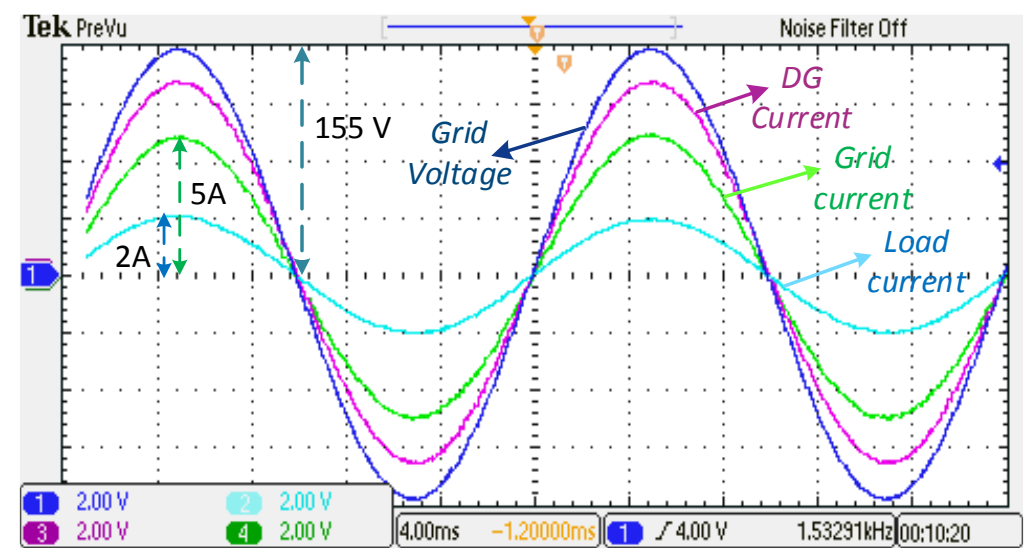

Fig. 7. Grid-tie operation of multilevel converter with ODC method 


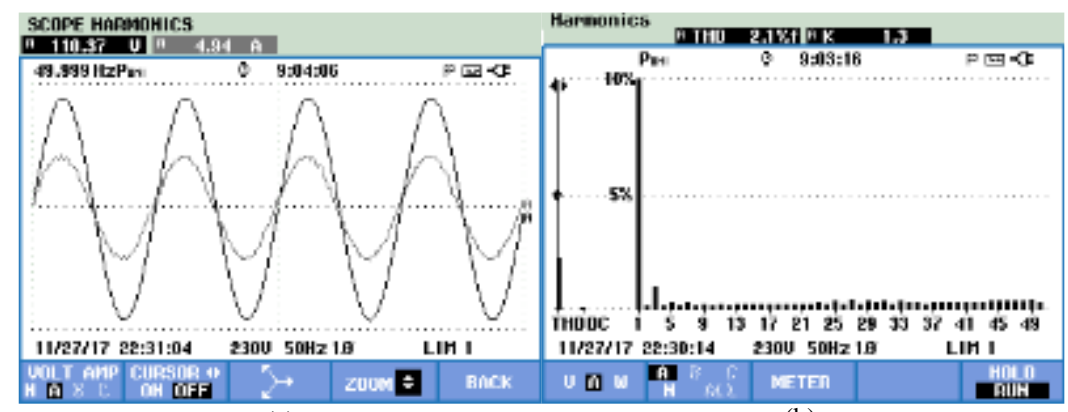

(a)

(b)

Fig. 8. (a) Grid voltage and DG current (b). Harmonic spectrum for grid current

\subsection{Active power filter mode of Opertion}

In the second test scenario, the multilevel inverter is playing the role of an improved active power filter to compensate the current harmonics which are made by non-linear loads. At the same time, this converter could inject active or reactive power to the grid. The multilevel inverter is controlled by an optimal direct control method to minimize the harmonic current injected to the main grid from microgrid. As it is shown in Fig. 9, the nonlinear load current is a harmonic current that should be fed either by main grid or microgrid, in the first case it will inject current harmonics into the main grid that may be out of the grid-connected microgrids harmonic limits and will cause problems for the grid. To overcome this problem the non-linear load, as well as the linear load, is fed by the DG inverter, the inverter used as the interface is a multilevel inverter which can output a wide variety of waveforms and the optimal direct control is applied to this converter to track the defined current reference. Fig. 9. Fig. 9 (a) shows the PCC current and voltage waveform before being compensated while Fig. 9 (b) illustrates the harmonic spectrum for PCC current before compensation. As it could be seen in Fig. 10 the multilevel inverter will inject harmonic current in addition to fundamental current to compensate the current harmonics, so that the grid current is almost harmonic free with the THD of $2.6 \%$. It is worth noting that the non-linear load current magnitude is significant in comparison to the DG current and THD will be much smaller by increasing the switching frequency of the multilevel inverter. Grid voltage and DG current waveform is shown in Fig. 11(a), Harmonic spectrum for compensated grid current is also shown in Fig. 11 (b).

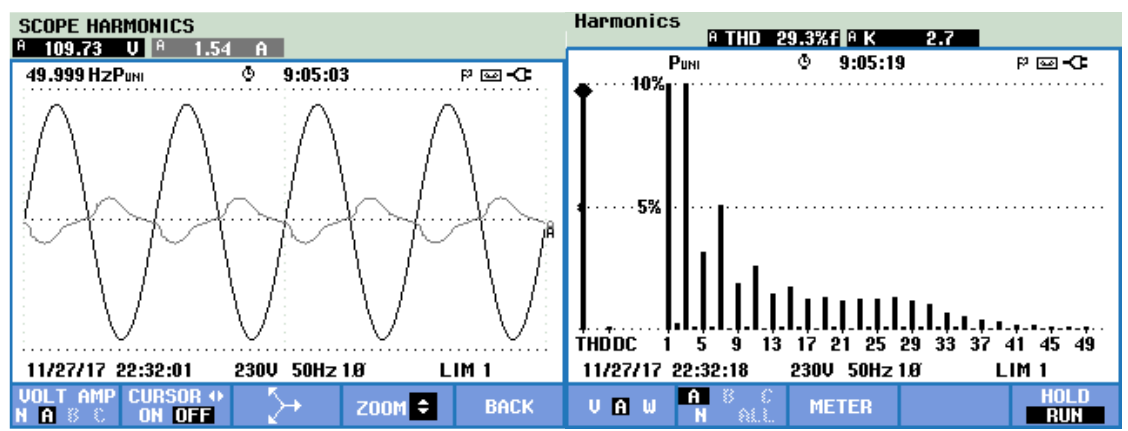

(a)

(b) 
Fig. 9. Voltage and current waveform of PCC before compensation. (b). Harmonic spectrum of PCC before compensation

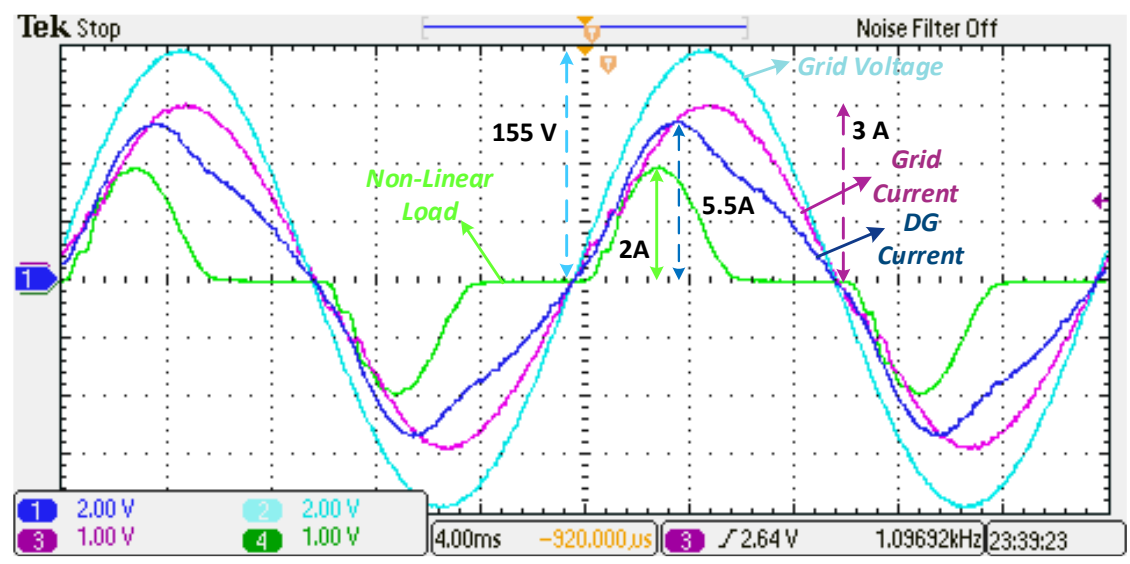

Fig. 10. Active power filter operation of the multilevel converter with optimal direct control method

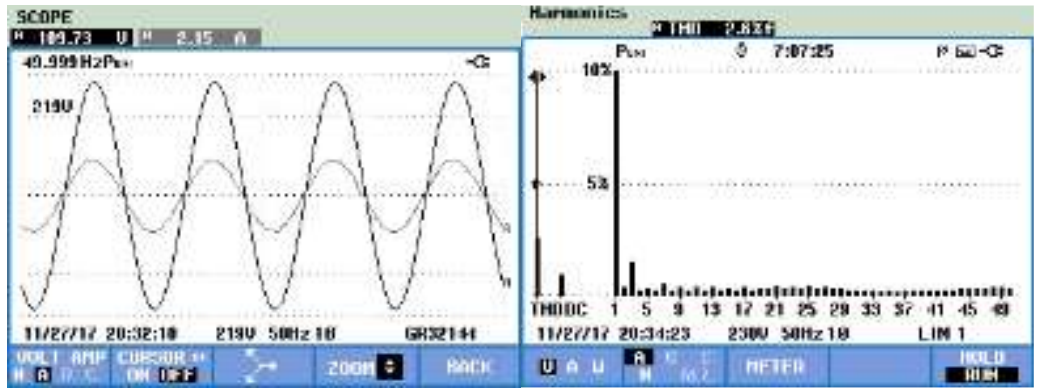

(a)

(b)

Fig. 11. (a) Grid voltage and grid current of PCC after compensation. (b). Harmonic spectrum of grid current after compensation

\subsection{Dynamic response of converter to changes}

In this scenario, the dynamic response of converter to a sudden change of current reference is being studied. As it could be seen in Fig. 12 the current reference of the converter has been changed from 70 percent of full load to 110 percent of load suddenly. As it could be seen in this figure the tracking error is being cleared in less than $1 \mathrm{~ms}$ that is much smaller than a full cycle. It is evidence of an improved dynamic response behavior of the proposed control method. This characteristic of the proposed control method makes it an appropriate solution for the applications that need high response speed such as active power filter. 


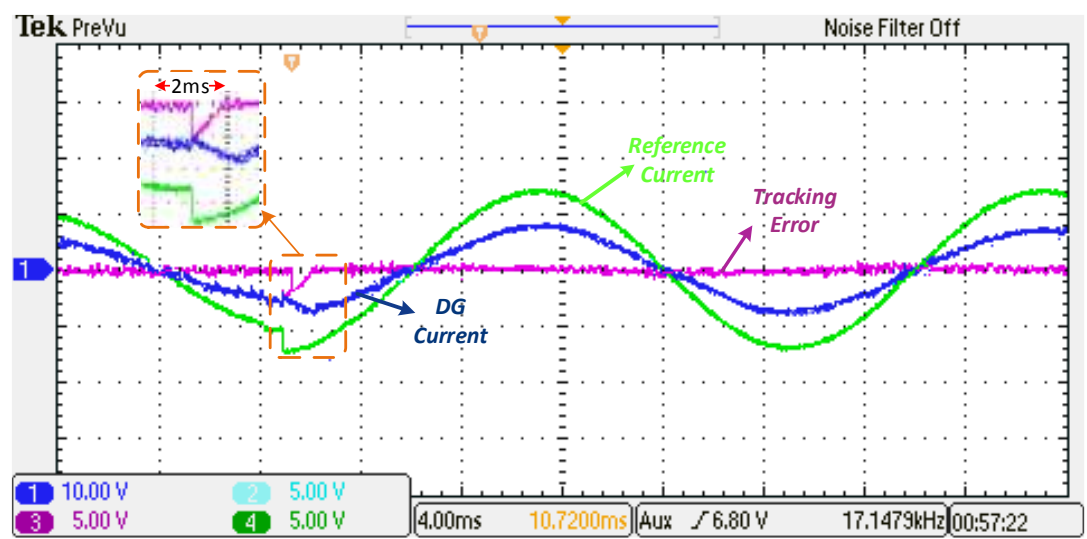

Fig. 12. Dynamic response of the control method to sudden reference changes

\section{CONCLUSION}

In this paper an optimal direct control method for a cascaded H-bridge multilevel inverter is proposed. High-speed response of this method to sudden changes makes it an appropriate control method for some critical applications such as active power filter. It is worth noting that to get much concise results, the processor calculation delay time is tried to be compensated in a way that has the minimum negative effect in the controller operation. To have a proof of over mentioned claims the control method was applied to a prototype of the converter in several operation conditions. At firs the conventional grid-connected operation of the converter using the proposed control method is being studied. In the second scenario, the converter is used as an improved active power filter which delivers active power to the loads as well as compensating the current harmonics. Finally the dynamic response of the converter to sudden changes was studied and it was proved that the control method could clear the transition to changes in less than $1 \mathrm{~ms}$ that is an improvement in the active power filter operation.

\section{REFERENCES}

[1] Nabae A, Takahashi I, Akagi H. A new neutral-point-clamped PWM inverter. IEEE Transactions on industry applications. 1981:518-23.

[2] Oskuee MRJ, Karimi M, Naderi Y, Ravadanegh SN, Hosseini SH. A new multilevel voltage source inverter configuration with minimum number of circuit elements. Journal of Central South University. 2017;24:912-20.

[3] Hosseini SH, Ravadanegh SN, Karimi M, Naderi Y, Oskuee MRJ. A new scheme of symmetric multilevel inverter with reduced number of circuit devices. Electrical and Electronics Engineering (ELECO), 2015 9th International Conference on: IEEE; 2015. p. 1072-8.

[4] Hosseini SH, Varesi K, Ardashir JF, Gandomi AA, Saeidabadi S. An attempt to improve output voltage quality of developed multi-level inverter topology by increasing the number of levels. Electrical and Electronics Engineering (ELECO), 2015 9th International Conference on: IEEE; 2015. p. 665-9.

[5] Naderi Y, Hosseini SH, Mahari A, Naderi R. A new strategy for harmonic minimization based on triple switching of multilevel converters. Electrical Engineering (ICEE), 2013 21st Iranian Conference on: IEEE; 2013. p. 1-6. 
[6] Tran Q-T, Truong AV, Le PM. Reduction of harmonics in grid-connected inverters using variable switching frequency. International Journal of Electrical Power \& Energy Systems. 2016;82:242-51.

[7] Wu F, Li X, Feng F, Gooi HB. Efficiency enhancement scheme of cascaded multilevel grid-connected inverter and its improvement to eliminate effect of non-ideal grid conditions. International Journal of Electrical Power \& Energy Systems. 2016;76:120-8.

[8] Biricik S, Komurcugil H. Three-level hysteresis current control strategy for three-phase four-switch shunt active filters. IET Power Electronics. 2016;9:1732-40.

[9] Lam CS, Wong MC, Han YD. Hysteresis current control of hybrid active power filters. IET Power Electronics. 2012;5:1175-87.

[10] Zarnaghi YN, Hosseini SH, Zadeh SG, Mohammadi-Ivatloo B, Quintero JCV, Guerrero JM. Distributed Power Quality Improvement in Residential Microgrids. Eleco 2017 10th International Ieee Conference on Electrical and Electronics Engineering: IEEE; 2017.

[11] Guerrero JM, Vasquez JC, Matas J, Vicuna D, García L, Castilla M. Hierarchical control of droop-controlled AC and DC microgrids-A general approach toward standardization. Industrial Electronics, IEEE Transactions on. 2011;58:158-72.

[12] Savaghebi M, Jalilian A, Vasquez JC, Guerrero JM. Secondary control scheme for voltage unbalance compensation in an islanded droop-controlled microgrid. IEEE Transactions on Smart Grid. 2012;3:797-807.

[13] Singh B, Dube SK, Arya SR. An improved control algorithm of DSTATCOM for power quality improvement. International Journal of Electrical Power \& Energy Systems. 2015;64:493-504.

[14] Mahela OP, Shaik AG. Power quality improvement in distribution network using DSTATCOM with battery energy storage system. International Journal of Electrical Power \& Energy Systems. 2016;83:229-40.

[15] Patjoshi RK, Kolluru VR, Mahapatra K. Power quality enhancement using fuzzy sliding mode based pulse width modulation control strategy for unified power quality conditioner. International Journal of Electrical Power \& Energy Systems. 2017;84:153-67.

[16] Ziouani I, Boukhetala D, Darcherif A-M, Amghar B, El Abbassi I. Hierarchical control for flexible microgrid based on three-phase voltage source inverters operated in parallel. International Journal of Electrical Power \& Energy Systems. 2018;95:188-201.

[17] Mirzaeva G, Goodwin GC, McGrath BP, Teixeira C, Rivera ME. A Generalized MPC Framework for the Design and Comparison of VSI Current Controllers. IEEE Transactions on Industrial Electronics. 2016;63:5816-26.

[18] Prodan I, Zio E. A model predictive control framework for reliable microgrid energy management. International Journal of Electrical Power \& Energy Systems. 2014;61:399-409.

[19] Falkowski P, Sikorski A. Finite Control Set Model Predictive Control for Grid-Connected AC\&\#8211;DC Converters With LCL Filter. IEEE Transactions on Industrial Electronics. 2018;65:2844-52.

[20] Tarisciotti L, Formentini A, Gaeta A, Degano M, Zanchetta P, Rabbeni R, et al. Model Predictive Control for Shunt Active Filters With Fixed Switching Frequency. IEEE Transactions on Industry Applications. 2017;53:296-304.

[21] Lei M, Yang Z, Wang Y, Xu H, Meng L, Vasquez JC, et al. An MPC-Based ESS Control Method for PV Power Smoothing Applications. IEEE Transactions on Power Electronics. 2018;33:2136-44.

[22] Bighash EZ, Sadeghzadeh SM, Ebrahimzadeh E, Blaabjerg F. Improving performance of LVRT capability in single-phase grid-tied PV inverters by a modelpredictive controller. International Journal of Electrical Power \& Energy Systems. 2018;98:176-88. 
[23] Lee SS, Heng YE. A tuning-less model predictive control for modular multilevel converter capable of unbalanced grid fault. International Journal of Electrical Power \& Energy Systems. 2018;94:213-24.

[24] Kwak S, Park J-C. Switching strategy based on model predictive control of VSI to obtain high efficiency and balanced loss distribution. IEEE Transactions on Power Electronics. 2014;29:4551-67.

[25] Fuentes E, Kalise D, Rodríguez J, Kennel RM. Cascade-free predictive speed control for electrical drives. IEEE Transactions on Industrial Electronics. 2014;61:217684.

[26] Babaei E. A Cascade Multilevel Converter Topology With Reduced Number of Switches. IEEE Transactions on Power Electronics. 2008;23:2657-64.

[27] Ma J, Song W, Wang S, Feng X. Model Predictive Direct Power Control for Single Phase Three-Level Rectifier at Low Switching Frequency. IEEE Transactions on Power Electronics. 2018;33:1050-62.

[28] Rodriguez J, Kazmierkowski MP, Espinoza JR, Zanchetta P, Abu-Rub H, Young HA, et al. State of the art of finite control set model predictive control in power electronics. IEEE Transactions on Industrial Informatics. 2013;9:1003-16.

[29] Geyer T, Papafotiou G, Morari M. Model predictive direct torque control—Part I: Concept, algorithm, and analysis. IEEE Transactions on Industrial Electronics. 2009;56:1894-905.

[30] Papafotiou G, Kley J, Papadopoulos KG, Bohren P, Morari M. Model predictive direct torque control—Part II: Implementation and experimental evaluation. IEEE Transactions on Industrial Electronics. 2009;56:1906-15.

[31] Geyer T. A comparison of control and modulation schemes for medium-voltage drives: Emerging predictive control concepts versus PWM-based schemes. IEEE Transactions on Industry Applications. 2011;47:1380-9.

[32] Rodriguez J, Pontt J, Silva CA, Correa P, Lezana P, Cortés P, et al. Predictive current control of a voltage source inverter. IEEE Transactions on Industrial Electronics. 2007;54:495-503.

[33] Cortes P, Rodriguez J, Silva C, Flores A. Delay compensation in model predictive current control of a three-phase inverter. IEEE Transactions on Industrial Electronics. 2012;59:1323-5.

[34] IEEE Recommended Practice and Requirements for Harmonic Control in Electric Power Systems - Redline. IEEE Std 519-2014 (Revision of IEEE Std 519-1992) - Redline. 2014:1-213. 